\title{
Isolation and characterization of phosphofungi, and screening of their plant growth-promoting activities
}

\author{
Xiaohui Wang ${ }^{1}$, Changdong Wang ${ }^{2}$, Junkang Sui ${ }^{1}$, Zhaoyang Liu², Qian $\mathrm{Li}^{2}$, Chao Ji ${ }^{2}$, Xin Song ${ }^{2}$, Yurong Hu${ }^{2}$, \\ Changqian Wang ${ }^{2}$, Rongbo Sa' , Jiamiao Zhang ${ }^{2}$, Jianfeng Du ${ }^{2}$ and Xunli Liu²*
}

\begin{abstract}
Rhizospheric microorganisms can increase phosphorus availability in the soil. In this regard, the ability of phosphofungi to dissolve insoluble phosphorus compounds is greater than that of phosphate-solubilizing bacteria. The aim of the current study was to identify efficient phosphofungi that could be developed as commercial microbial agents. Among several phosphate-solubilizing fungal isolates screened, strain CS-1 showed the highest phosphorus-solubilization ability. Based on phylogenetic analysis of the internal transcribed spacer region sequence, it was identified as Aspergillus niger. High-performance liquid chromatography analysis revealed that the mechanism of phosphorus solubilization by CS-1 involved the synthesis and secretion of organic acids, mainly oxalic, tartaric, and citric acids. Furthermore, strain CS-1 exhibited other growth-promoting abilities, including efficient potassium release and degradation of crop straw cellulose. These properties help to returning crop residues to the soil, thereby increasing nutrient availability and sustaining organic matter concentration therein. A pot experiment revealed that CS-1 apparently increased the assessed biometric parameters of wheat seedlings, implying the potential of this strain to be developed as a commercial microbial agent. We used Illumina MiSeq sequencing to investigate the microbial community composition in the rhizosphere of uninoculated wheat plants and wheat plants inoculated with the CS-1 strain to obtain insight into the effect of the CS-1 strain inoculation. The data clearly demonstrated that CS-1 significantly reduced the content of pathogenic fungi, including Gibberella, Fusarium, Monographella, Bipolaris, and Volutella, which cause soil-borne diseases in various crops. Strain CS-1 may hence be developed into a microbial agent for plant growth improvement.
\end{abstract}

Keywords: Aspergillus niger, Growth-promoting ability, HPLC, Illumina MiSeq sequencing, Phosphofungi

\section{Introduction}

Phosphorus is the second most important limiting element required for plant growth (Chai et al. 2011; Li et al. 2015a; Ram et al. 2015), and it cannot be substituted by any other nutrient. However, even though soils may contain a substantial reserve of total phosphorus (Collavino et al. 2010), most natural soils are typically deficient in this element. This is particularly true for highly weathered soils, in which phosphorus forms insoluble complexes with aluminum, iron, and hydroxides (in acidic

\footnotetext{
*Correspondence: xunliliu@163.com

${ }^{2}$ College of Forestry, Shandong Agricultural Universities, No. 61, Daizong Street, Taian 271018, Shandong, China

Full list of author information is available at the end of the article
}

soils), and with calcium (in alkaline soils) (Mendez 2014). To sustain crop production, the traditional method of rectifying phosphorus deficiency involved applying large amounts of phosphate fertilizers to the soil. However, only a small fraction of this added phosphate is available to plants, whereas a considerable proportion becomes immobilized after application (Singh 2011). This not only increases production costs but also leads to environmental pollution.

An alternative strategy involves a direct application of locally available rock phosphate (RP) to the soil; however, the effectiveness of RP as a fertilizer is highly dependent on the soil type, with the $\mathrm{pH}$ playing a particularly important role (Sulbarán et al. 2009). In this regard, Nahas (1996) reported a high correlation between the final $\mathrm{pH}$ 
and soluble phosphate content, with a decrease in $\mathrm{pH}$ directly influencing the solubilization of RP. Furthermore, $\mathrm{RP}$ is a non-renewable resource, and as such, its use as a fertilizer is not fully in accord with the current principles of sustainability (Ram et al. 2015).

It is well known that a number of bacteria and fungi are able to solubilize elemental phosphorus from insoluble RP for plant growth, and that fungi have a more pronounced ability to dissolve insoluble phosphorus compounds and have more stable genetic traits than those of bacteria (Gyaneshwar et al. 1998; Joseph and Jisha 2009; Rmn 1983). Collectively, such bacteria and fungi are referred to as phosphate-solubilizing microorganisms (PSMs), and include genera such as Pseudomonas, Bacillus, and Rhizobium (bacteria), and Aspergillus and Penicillium (fungi). Phosphorus-solubilizing activity is considered to be the most important among the multiple properties of the soil microorganisms that promote plant growth and nutrient absorption (Rodríguez and Fraga 1999). However, the growth-promoting effects of these PSMs are also influenced by environmental factors, including the compositional characteristics, organic matter content, texture, moisture, and $\mathrm{pH}$ of the soil, as well as the activities of certain enzymes (Ponmurugan and Gopi 2006). In addition, when introduced into the environment, PSMs should be able to compete with other soil microflora and successfully colonize the rhizosphere of crops. In this regard, there is a substantial advantage in using natural soil isolates as potential inoculants and in the same area from which they were isolated.

Thus far, research on PSMs has been insufficient, and few such organisms have been considered for exploitation as microbial fertilizer strains (Collavino et al. 2010; Yin et al. 2015). Given these considerations, the aim of the current study was to identify efficient phosphofungi from wheat rhizosphere soil that have the potential to be developed as commercial microbial agents.

\section{Materials and methods Soil sampling}

The study site was a wheat field located in Taian City, Shandong Province, China. Wheat seedlings at the grainfilling stage were uprooted with intact roots and adhering soil from various sampling points. The aerial parts were excised using a sterilized knife, and the residual root portions were transferred to sterilized plastic bags $(12 \times 24 \mathrm{~cm})$, which were labeled, sealed, placed in an icebox, immediately transported to the laboratory, and stored at $4{ }^{\circ} \mathrm{C}$ until use in subsequent experiments.

\section{Isolation and screening of phosphofungi}

Non-rhizosphere soil was removed by gentle shaking, leaving behind only the rhizosphere soil. The rhizosphere soil was collected from roots by dipping and gentle shaking in sterile distilled water under aseptic conditions, and mixed on a table concentrator for $30 \mathrm{~min}$. The resultant soil solution was then serially diluted up to $10^{-6}$-fold, and the respective dilutions were plated on Martin agar medium supplemented with $30 \mu \mathrm{g} / \mathrm{mL}$ streptomycin, and incubated at $28 \pm 2{ }^{\circ} \mathrm{C}$ for $2-3$ days (Bonito et al. 2016; Mehta and Nautiyal 2001). Colonies showing the predominant morphology were selected at random from each plate; isolates showing various colony morphologies were purified and screened for their phosphatesolubilizing ability. Overall, 20 colonies were incubated for 5-7 days on the National Botanical Research Institute phosphate growth (NBRIP) medium (Nautiyal et al. 2000). Halo formation around the colonies was considered to be indicative of phosphate-solubilization activity (Mehta and Nautiyal 2001).

\section{Phosphate-solubilization efficiency in liquid medium}

Quantitative estimation of the phosphate-solubilization ability of the fungal isolates in broth was carried out using $50 \mathrm{~mL}$ of the NBRIP growth medium in 250-mL conical flasks inoculated with $1 \mathrm{~mL}$ of spore suspensions [inoculum concentration was with approximately $2-6 \times 10^{8}$ colony-forming units (CFUs)/mL]. The NBRIP growth medium contained as follows (per $1 \mathrm{~L}$ ): $\mathrm{Ca}_{3}\left(\mathrm{PO}_{4}\right)_{2}, 5.0 \mathrm{~g}$; glucose, $10 \mathrm{~g}$; $\left(\mathrm{NH}_{4}\right)_{2} \mathrm{SO}_{4}, 0.5 \mathrm{~g} ; \mathrm{NaCl}, 0.3 \mathrm{~g} ; \mathrm{KCl}, 0.3 \mathrm{~g}$; $\mathrm{MgSO}_{4} \cdot 7 \mathrm{H}_{2} \mathrm{O}, 0.3 \mathrm{~g} ; \mathrm{FeSO}_{4}, 0.03$ g; and $\mathrm{MnSO}_{4}, 1.0 \mathrm{~g}$, natural $\mathrm{pH}$ (5.51). The uninoculated medium served as a control. The inoculated medium was incubated at $30{ }^{\circ} \mathrm{C}$ and $200 \mathrm{r} / \mathrm{min}$ in the dark for 5 days. The entire experiment was performed in triplicate. Cultures were harvested by centrifugation at $1073 \times g$ for $10 \mathrm{~min}$, and the supernatant was used in quantitative analysis. The amount of soluble phosphorus in the culture supernatant was estimated using the molybdenum blue method (Bray 1945). The results are expressed as mean values with standard deviations.

\section{DNA extraction, PCR amplification, and phylogenetic analysis}

Mycelia were harvested after 4 days of growth on potato dextrose agar medium at $28 \pm 2{ }^{\circ} \mathrm{C}$ and genomic DNA was extracted using an HP Fungal DNA kit (TransGen Biotech, Beijing, China), by following the manufacturer's protocol. rDNA internal transcribed spacer (ITS) fragments were amplified using the universal fungal primers ITS1 and ITS4 (Pitkäranta et al. 2008). The obtained amplicons were sequenced by a commercial sequencing company (Sangon Biotech, Shanghai, China). The obtained nucleotide sequences were analyzed and compared with the ones deposited in the GenBank database using BLAST (https://blast.ncbi.nlm.nih.gov/Blast. 
cgi). A phylogenetic tree was constructed based on the neighbor-joining method. Genetic distances and similarity between the selected strains were computed using the maximum composite likelihood algorithm. The phylogenetic tree was constructed using MEGA 5.1 software (Mendez 2014), and the reliability of the tree topology was evaluated by bootstrap analysis with 1000 replicates.

\section{Dynamics of the phosphorus-solubilization mechanism of PSMs}

The spore suspension (an inoculum containing approximately 2-6 $\times 10^{8} \mathrm{CFUs} / \mathrm{mL}$ ) of the selected phosphatesolubilizing fungal (PSF) isolate was incubated in $50 \mathrm{~mL}$ of the NBRIP growth medium at $30{ }^{\circ} \mathrm{C}$ and $200 \mathrm{r} / \mathrm{min}$ in the dark for several days. An uninoculated medium served as a control. The culture supernatant was harvested by centrifugation at $1073 \times g$ for $10 \mathrm{~min}$, daily, and then passed through a $0.22-\mu \mathrm{m}$ sterile filter membrane. The $\mathrm{pH}$, low-molecular-weight organic acids, and inorganic phosphate content of the supernatant were determined (Singh 2011). Fungal cell pellets were collected and dried in an oven at $70{ }^{\circ} \mathrm{C}$ to a constant weight, to determine the dry weight of the mycelium biomass (Mendes et al. 2013). The entire experiment was performed in triplicate, and the data are expressed as mean values with standard deviations.

Qualitative and quantitative analyses of organic acids in the culture supernatants were performed using an Agilent ZORBAX SB-Aq high-performance liquid chromatography (HPLC) system (Agilent Technologies, Inc., Santa Clara, CA, USA). Thermo C18 $(250 \mathrm{~mm} \times 4.6 \mathrm{~mm}$, $5 \mu \mathrm{m})$ column was used (Agilent Technologies, Inc.). The mobile phase was $50 \mathrm{mM} \mathrm{KH_{2 }} \mathrm{PO} 4(\mathrm{pH} \mathrm{2.70)}$ and $\mathrm{CH}_{3} \mathrm{OH}$ (97:3); total run time was $30 \mathrm{~min}$, with a flow rate of $0.8 \mathrm{~mL} / \mathrm{min}$; the injection volume was $2 \mu \mathrm{L}$; and the detection wavelength was $210 \mathrm{~nm}$, with the analysis performed at $25^{\circ} \mathrm{C}$.

\section{Potassium-solubilization efficiency}

Based on the similarity mechanisms of phosphorus and potassium-solubilization mechanisms, quantitative estimation of potassium-solubilization efficiency was conducted in silicate fermentation broth containing the following ingredients (per $1 \mathrm{~L}$ ): sucrose, $10.0 \mathrm{~g}$; $\left(\mathrm{NH}_{4}\right)_{2} \mathrm{SO}_{4}, 0.2 \mathrm{~g} ; \mathrm{MgSO}_{4} \cdot 7 \mathrm{H}_{2} \mathrm{O}, 0.5 \mathrm{~g} ; \mathrm{NaCl}, 0.1 \mathrm{~g}$; $\mathrm{CaCO}_{3}, 0.1 \mathrm{~g}$; and feldspar powder, $5.0 \mathrm{~g}, \mathrm{pH} 7.0 \pm 0.2$ (Joseph and Jisha 2009). The culture was incubated at $30{ }^{\circ} \mathrm{C}$ and $200 \mathrm{r} / \mathrm{min}$ in the dark, and the entire experiment was performed in triplicate. After 7 days, the culture was treated with $2 \% \mathrm{H}_{2} \mathrm{O}_{2}$, filtered into a $100-\mathrm{mL}$ volumetric flask mineral powder residues, and then diluted to $100 \mathrm{~mL}$ with distilled water. The potassium content in the filtrate was determined by flame photometry (Huang and ChengQun 2010). The data are expressed as mean values with standard deviations.

\section{Cellulase and hemicellulase activities}

Isolates were inoculated into cellulase and hemicellulase fermentation media, respectively, and incubated at $200 \mathrm{r} /$ min and $30{ }^{\circ} \mathrm{C}$ for $2-8$ days. The cellulase fermentation medium contained (per $1 \mathrm{~L}$ ): wheat bran, $40 \mathrm{~g}$; peptone, 30 g; $\left(\mathrm{NH}_{4}\right)_{2} \mathrm{SO}_{4}, 2.0$ g; $\mathrm{Na}_{2} \mathrm{HPO}_{4}, 0.5$ g; $\mathrm{MgSO}_{4}, 0.2$ g; $\mathrm{FeSO}_{4} \cdot 7 \mathrm{H}_{2} \mathrm{O}, 0.1 \mathrm{~g}$; and $\mathrm{CaCO}_{3}, 0.5 \mathrm{~g}$. The hemicellulase fermentation medium contained (per $1 \mathrm{~L}$ ): wheat bran, $40 \mathrm{~g}$; peptone, $5.0 \mathrm{~g}$; $\left(\mathrm{NH}_{4}\right)_{2} \mathrm{SO}_{4}, 3.0 \mathrm{~g} ; \mathrm{KH}_{2} \mathrm{PO}_{4}$, 5 g; $\mathrm{MgSO}_{4}, 1 \mathrm{~g} ; \mathrm{CaCO}_{3}, 20 \mathrm{~g} ; \mathrm{NaCl}, 0.5 \mathrm{~g} ; \mathrm{KCl}, 0.5$ g; glucose, $1 \mathrm{~g}$; and Tween $80,1 \mathrm{~mL}$. Cells were separated from the cultivation medium by centrifugation at $1073 \times g$ for $10 \mathrm{~min}$ at $4{ }^{\circ} \mathrm{C}$, and the supernatants were used as the source of extracellular crude enzyme. Cellulase and hemicellulase activities were determined based on the increase in glucose released from sodium carboxymethyl cellulose and oat xylan, respectively (Miller 1959). One unit of cellulase and hemicellulase activity was defined as the amount of enzyme that produces $1 \mu \mathrm{mol}$ glucose equivalent per min under the assay conditions. The absorbance was measured using a UV spectrophotometer at $540 \mathrm{~nm}$. The increase in the amount of glucose released was determined using a glucose standard curve. The entire experiment was performed in triplicate, and the data are expressed as mean values with standard deviations.

\section{Pot experiment design}

To assess the effect of the isolates on plant growth, as bio-inoculants, a pot experiment was conducted on wheat using a randomized complete block design with three replicates for each treatment, where with 10 pots per each replicate. Wheat seeds were surface-sterilized with $75 \%$ ethanol for $1 \mathrm{~min}$, followed by $1 \%$ sodium hypochlorite for $30 \mathrm{~min}$, and extensive wash with sterile water (Collavino et al. 2010). Five sterilized wheat seeds were sown in 10-L clay tile pots containing soil collected from a local field under wheat cultivation. Two treatments were designed (control and CS- 1 strain) and performed under natural environmental conditions. For the CS-1 treatment, the roots of 1-week-old plantlets were inoculated with $15 \mathrm{~mL}$ of a spore suspension containing fungal spores suspended in sterile water at a density of approximately $10^{7} \mathrm{CFUs} / \mathrm{mL}$. The roots of the control plantlets were inoculated with the same volume of sterile water (Wei et al. 2017). All the pots were irrigated once before sowing to ensure correct seed germination, and then regularly watered during crop growth as per agronomic practices (Reddy and Sudhakara 2014). After 2 months, the wheat seedlings were uprooted separately 
to determine plant biomass indices. The rhizosphere soil was then carefully collected from 10 random soil cores from pots, and the samples were pooled to yield one composite sample per replicate. The soil samples were passed through a 2-mm sieve, thoroughly homogenized, and stored at $-80{ }^{\circ} \mathrm{C}$ for the analysis of microbial community structure.

\section{PCR amplification and Illumina MiSeq sequencing}

To ascertain whether and how the CS-1 strain exerted a positive on the microbial community structure in the wheat rhizosphere, Illumina MiSeq sequencing was used to investigate the differences in microbial communities in the rhizosphere of uninoculated wheat plants and wheat plants inoculated with the CS-1 strain. Total soil genomic DNA was extracted using the Soil DNA kit (USA OMEGA, Bio-Tek, Guangzhou, China), according to the manufacturer's instructions. The V4-V5 regions of the bacterial $16 S$ rRNA gene were amplified by using the following primers: 515F (5'-barcode-GTGCCAGCMGCCGCGG-3') and 907R (5'-CCGTCAATTCMTTTRAGTTT-3'). The ITS rDNA genes from fungal genomic DNA were amplified with the barcoded primers ITS1F (5'-barcode-CTTGGTCATTTAGAGGAAGTAA-3') and 2043R (5'-GCTGCGTTCTTCATCGATGC-3'). The "barcode" is an eight-base sequence unique to each sample. Amplicons were extracted from $2 \%$ agarose gels, purified using the AxyPrep DNA Gel Extraction kit (Axygen Biosciences, Union City, CA, USA), and quantified using QuantiFluor $^{\mathrm{TM}}$-ST (Promega, Madison, WI, USA). Purified amplicons were pooled in equimolar amounts and paired-end sequenced $(2 \times 250)$ on an Illumina MiSeq platform according to the standard protocols.

\section{Processing of Illumina MiSeq sequencing data}

Raw fastq files were demultiplexed and quality-filtered using QIIME (http://qiime.sourceforge.net/) with the following criteria. (i) The 300 -bp reads were truncated at any site with an average quality score of $<20$ over a 50-bp sliding window, discarding the truncated reads shorter than 50 bp. (ii) Reads with exact barcode matching, primer matching with a two-nucleotide mismatch, and reads containing ambiguous characters were removed. (iii) Only sequences with overlaps longer than $10 \mathrm{bp}$ were assembled according to their overlap sequence. Reads that could not be assembled were discarded. Operational taxonomic units (OTUs) were clustered with $97 \%$ similarity cut off using UPARSE (version 7.1; http://drive5. com/uparse/), and chimeric sequences were identified and removed using UCHIME (Zheng et al. 2015). The taxonomy of each $16 S$ rRNA gene sequence was analyzed by RDP Classifier (http://rdp.cme.msu.edu/) against the
Silva (SSU123) $16 S$ rRNA database using a confidence threshold of 70\%. The taxonomy of each ITS rDNA gene sequence was analyzed by RDP Classifier against the UNITE 7.0/ITS database (Abarenkov et al. 2010) using a confidence threshold of $70 \%$. To describe community diversity and richness, rarefaction data, Simpson, Shannon, Chao, and ACE indices were created using mothur (http://www.mothur.org/) (Schloss et al. 2009). Raw Illumina sequencing data from the current study were submitted to the NCBI Sequence Read Archive (SRA) under the Accession Number SRP132621.

\section{Statistical analysis}

All experiments were performed in triplicate, and all statistical analyses were performed using SAS version 8.0 software (SAS Institute, Inc.). Differences in mean values were considered significant when $P<0.05$. The histogram was created using Microsoft Excel 2010 (Microsoft, Redmond, WA, USA).

\section{Results \\ Isolation and screening of phosphofungi}

The production of clear zones around colonies on NBRIP medium is an indication that the organism has phosphate-solubilizing ability. In the present study, 20 fungal strains were isolated from a wheat field sampling site, only eight of which (CS-1 to CS-8) showed phosphate-solubilizing capacity. These isolates were further compared by culturing in the NBRIP liquid medium supplemented with Tricalcium phosphate (TCP)(equivalent to $0.1 \mathrm{~g}$ phosphorus per $100 \mathrm{~mL}$ of medium). As shown in Fig. 1, among these eight strains, CS-1 exhibited the highest phosphate solubilization $(790.67 \mathrm{mg} / \mathrm{L})$. The CS-1 strain was therefore selected for experiments determining its other growth-promoting qualities. On the basis

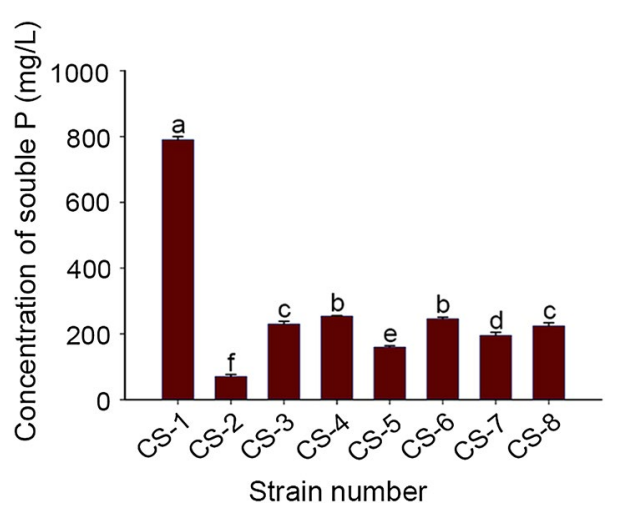

Fig. 1 Evaluation of the phosphate solubilising ability of the selected fungi in NBRIP medium. Soluble phosphorus (P) accumulation in cultures of different fungal strains grown on NBRIP medium. Error bars indicate standard errors $(n=3)$. Columns with different letters are significantly different $(P<0.05)$ according to the Student's $t$-test 
of the similar mechanisms of phosphorus and potassium solubilization, the CS-1 strain was also shown to promote efficient potassium release in silicate liquid medium supplemented with feldspar powder. Compared with the control, strain CS-1 led a $127.59 \%$ increase in potassium release.

\section{Identification and phylogenetic analysis of the CS-1 strain}

Since strain CS-1 showed the highest phosphate-solubilizing and potassium-dissolving indices among the eight isolates exhibiting phosphate-solubilizing capacity, it was subjected to molecular taxonomy analysis for identification. Based on the phylogenetic analysis of rDNA ITS region sequence, the strain CS-1 was identified as Aspergillus niger and has been deposited in the China General Microbiological Culture Collection Center (CGMCC) under the accession numbers CGMCC No. 14634.

\section{Dynamics of the phosphorus-solubilization mechanism of the CS-1 strain}

It is generally accepted that phosphate solubilization is linked to a decrease in medium $\mathrm{pH}$. In the current study, the CS-1 strain was inoculated into the NBRIP growth medium to determine the dynamics of its phosphatesolubilization mechanism. The experiment revealed that the $\mathrm{pH}$ of the NBRIP medium decreased with an increasing incubation time and that the final $\mathrm{pH}$ remained at approximately $2-3$ (Table 1 ), which was consistent with the results presented by Liang et al. (Liang et al. 2011). The biomass of CS-1 strain mycelium increased during the first $3 \mathrm{~d}$ of growth, reaching a maximum on the third day, and thereafter, gradually stabilizing before eventually declining (Table 1). Soluble phosphorus content increased to $626 \pm 8.50 \mathrm{mg} / \mathrm{L}$ in the early growth period, during which it was rapidly solubilized, whereas in the later stages, the dissolved phosphorus content did not significantly increase (Table 1). The HPLC analysis indicated that the mechanism of phosphorus solubilization by strain CS-1 mainly proceeded via the production of oxalic acid $(255.74 \mathrm{mg} / \mathrm{kg})$, tartaric acid $(201.25 \mathrm{mg} /$ $\mathrm{kg})$, and citric acid $(108.04 \mathrm{mg} / \mathrm{kg})$ in the NBRIP medium (Fig. 2).

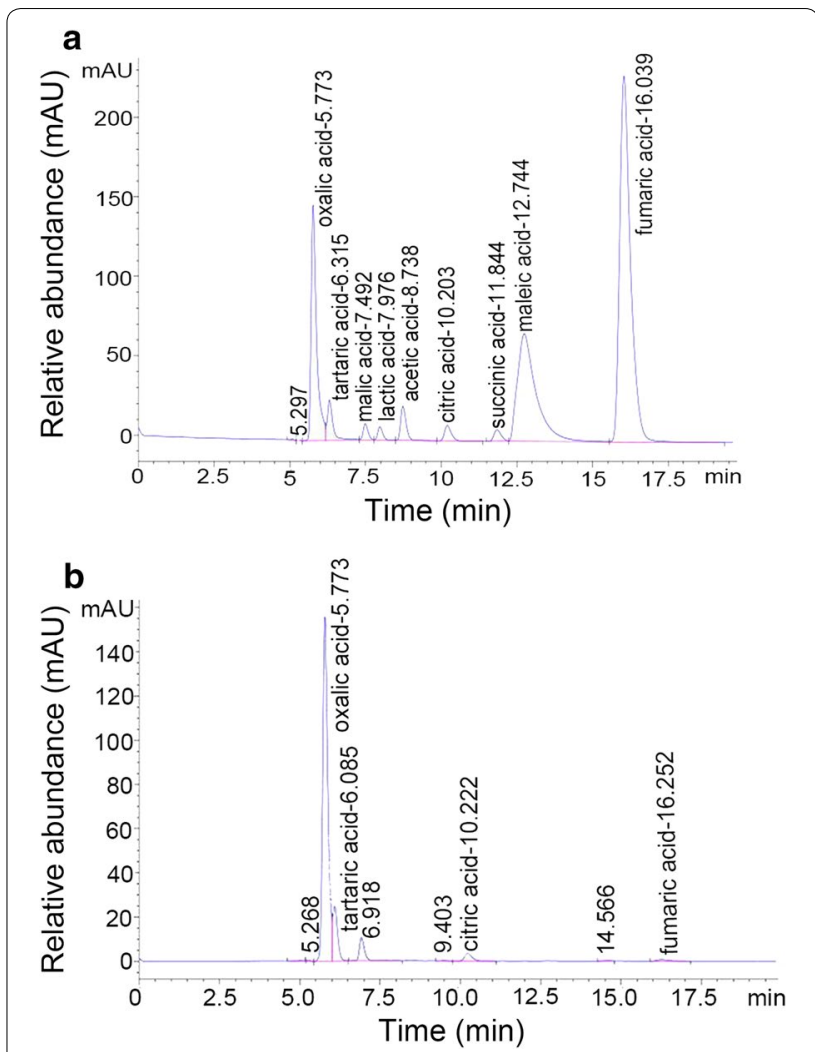

Fig. 2 Analyses of organic acids secreted by CS-1 strain were performed by HPLC. HPLC analysis of organic acids. a Chromatogram of a standard solution containing the following organic acids: oxalic, tartaric, malic, lactic acid, acetic, citric, succinic, maleic, and fumaric acid. $\mathbf{b}$ Chromatogram of a 3-day-old culture medium inoculated with strain CS-1, mainly containing oxalic, tartaric, and citric acid

\section{Cellulase and hemicellulase activities}

In addition to phosphate-solubilizing and potassiumrelease abilities, cellulase and hemicellulase activities of the CS-1 strain were also evaluated. The CS-1 strain was, accordingly, cultivated in cellulase and hemicellulase liquid fermentation media and the effects of culture time on the amount of cellulose- and hemicellulosedegrading enzymes produced by CS-1 were determined and compared. As shown in Table 2, the maximal cellulase and hemicellulase activities were $553.39 \pm 76.61$

Table 1 Effect of incubation period on the phosphate-solubilizing efficiency of the CS-1 strain

\begin{tabular}{lrrrrr}
\hline Index & \multicolumn{1}{c}{ 1 day } & 2 days & 3 days & 4 days & 5 days \\
\hline $\mathrm{pH}$ & $3.71 \pm 0.02 \mathrm{~b}$ & $3.23 \pm 0.41 \mathrm{c}$ & $2.45 \pm 0.26 \mathrm{~d}$ & $2.39 \pm 0.11 \mathrm{~d}$ & $2.34 \pm 0.07 \mathrm{~d}$ \\
Weight $_{\text {(dry weight/g) }}$ & $0.18 \pm 0.023 \mathrm{~d}$ & $0.27 \pm 0.013 \mathrm{c}$ & $0.32 \pm 0.007 \mathrm{a}$ & $0.30 \pm 0.007 \mathrm{ab}$ & $0.29 \pm 0.004 \mathrm{bc}$ \\
$\mathrm{P}_{(\text {Increment } \mathrm{mg} / \mathrm{L})}$ & $374.05 \pm 53.95 \mathrm{~b}$ & $617.27 \pm 34.00 \mathrm{a}$ & $626.52 \pm 8.50 \mathrm{a}$ & $646.92 \pm 5.55 \mathrm{a}$ & $663.63 \pm 22.26 \mathrm{a}$ \\
\hline
\end{tabular}

Values are mean $\pm S D(n=3)$. Means sharing a common letter within the same column are not significantly different at $P<0.05$ 
and $2979.09 \pm 88.68 \mathrm{U} / \mathrm{mL}$ after 6 and 3 days of culture, respectively.

\section{Pot experiment \\ Biomass accumulation}

Phosphate-solubilizing bacteria (PSB) have been used as bio-inoculant preparations to improve the growth of plants. On the basis of the aforementioned observations, a pot experiment was conducted to evaluate the practical application of strain CS-1 isolated in the present study. The effect of CS-1 inoculation on plant growth was assessed under natural environmental conditions. Accordingly, strain CS-1 exhibited a stimulatory effect on the growth parameters of wheat seedlings (Table 3), increasing the plant dry biomass (by 23.3\%), fresh biomass (by $23.8 \%$ ), and the root/shoot ratio (31.5\%) of wheat, compared with the control group. Although the CS-1 strain did not significantly affect the root length and shoot height, the wheat seedlings treated with this strain had a greater number of lateral roots (Additional file 1:
Fig. S1). This would be beneficial for the wheat seedlings, enabling them to obtaining sufficient water and nutrients from the soil.

\section{Illumina MiSeq sequencing and sequence analysis}

More than 20,000 bacterial and 30,000 fungal valid reads were obtained for each replicate a sequence optimization process. Using a 3\% dissimilarity cut-off for clustering, the reads were grouped into different OTUs (Table 4). Rarefaction curves (Fig. 3a, b) for the bacterial and fungal communities at distance levels of 0.03 did not fully represent the number of different bacterial and fungal communities, while the Shannon diversity curves approached a plateau with the increase in sequencing number (Fig. 3c, d). Furthermore, the coverage was approximately $>99 \%$. Therefore, the sequencing capability was sufficiently large to capture the complete diversity of these communities. The Chao and ACE values are indicators of species richness, and Shannon and Simpson indices are indicators of species diversity (Liu et al. 2015). The bacterial

Table 2 Effect of incubation period on the activity of enzymes produced by the CS-1 strain

\begin{tabular}{|c|c|c|c|c|c|c|c|}
\hline \multirow{2}{*}{$\begin{array}{l}\text { Enzyme } \\
\text { activity }\end{array}$} & \multicolumn{7}{|c|}{ Incubation time (days) } \\
\hline & 2 days & 3 days & 4 days & 5 days & $6 d$ & $7 d$ & $8 d$ \\
\hline $\begin{array}{l}\text { Cellulase } \\
(\mathrm{U} / \mathrm{mL})\end{array}$ & $1.43 \pm 0.56 \mathrm{~d}$ & $124.05 \pm 1.15 d$ & $159.29 \pm 59.96 c$ & $375.84 \pm 21.17 b$ & $553.39 \pm 76.61 a$ & $345.53 \pm 47.68 b$ & $347.85 \pm 13.57 b$ \\
\hline $\begin{array}{l}\text { Hemicel- } \\
\text { lulase (U/ } \\
\text { mL) }\end{array}$ & $2743.78 \pm 55.97 b$ & $2979.09 \pm 8888.68 a$ & $1655.41 \pm 159.54 a b$ & $1269.75 \pm 53.02 c$ & $1251.70 \pm 16.34 c$ & $997.92 \pm 28.90 c$ & - \\
\hline
\end{tabular}

Values are mean $\pm S D(n=3)$. Means sharing a common letter within the same column are not significantly different at $P<0.05$

Table 3 Effect of the CS-1 strain on growth parameters of wheat seedling

\begin{tabular}{llllc}
\hline Treatment & Shoot height $(\mathbf{c m})$ & Root length $(\mathbf{c m})$ & Dry weight $(\mathbf{g})$ & Fresh weight $(\mathbf{g})$ \\
\hline CK & $40.76 \pm 0.83 \mathrm{a}$ & $17.78 \pm 1.16 \mathrm{a}$ & $0.30 \pm 0.04 \mathrm{~b}$ & $1.26 \pm 0.16 \mathrm{~b}$ \\
CS-1 & $40.53 \pm 1.20 \mathrm{a}$ & $18.15 \pm 1.77 \mathrm{a}$ & $0.37 \pm 0.05 \mathrm{a}$ & $1.56 \pm 0.06 \mathrm{a}$ \\
\hline
\end{tabular}

Values are mean $\pm S D(n=30)$. Means sharing a common letter within the same column are not significantly different at $P<0.05$. "CS-1" denotes wheat seedlings treated with a suspension of strain CS-1 spores. "CK" denotes wheat seedlings treated with an equal volume of sterile water

Table 4 Diversity and richness indices of bacterial and fungal community from CS-1 treatment and control

\begin{tabular}{|c|c|c|c|c|}
\hline \multirow[t]{2}{*}{ Index } & \multicolumn{2}{|l|}{ Bacteria } & \multicolumn{2}{|l|}{ Fungi } \\
\hline & CK & CS-1 & CK & CS-1 \\
\hline OTU & $1895.33 \pm 38.66 a$ & $1868.33 \pm 7.54 \mathrm{a}$ & $539.67 \pm 7.13 a$ & $393.67 \pm 49.57 b$ \\
\hline Shannon & $4.39 \pm 0.52 \mathrm{a}$ & $4.46 \pm 0.09 a$ & $3.83 \pm 0.17 a$ & $2.98 \pm 0.48 b$ \\
\hline Simpson & $0.05 \pm 0.04 a$ & $0.03 \pm 0.01 a$ & $0.062 \pm 0.02 \mathrm{a}$ & $0.14 \pm 0.02 a$ \\
\hline Ace & $412.75 \pm 9.22 \mathrm{a}$ & $406.65 \pm 9.35 a$ & $611.01 \pm 14.97 a$ & $502.11 \pm 26.11 b$ \\
\hline Chao & $414.42 \pm 5.71 a$ & $417.76 \pm 17.06 a$ & $588.30 \pm 43.30 a$ & $478.36 \pm 12.77 b$ \\
\hline Coverage & 0.9978 & 0.9977 & 0.9966 & 0.9963 \\
\hline
\end{tabular}

Chao and ACE value are indicators of species richness. Shannon and Simpson are indicators of species diversity. Values are mean \pm SD $(n=3)$. Means sharing a common letter within the same column are not significantly different at $P<0.05$ 

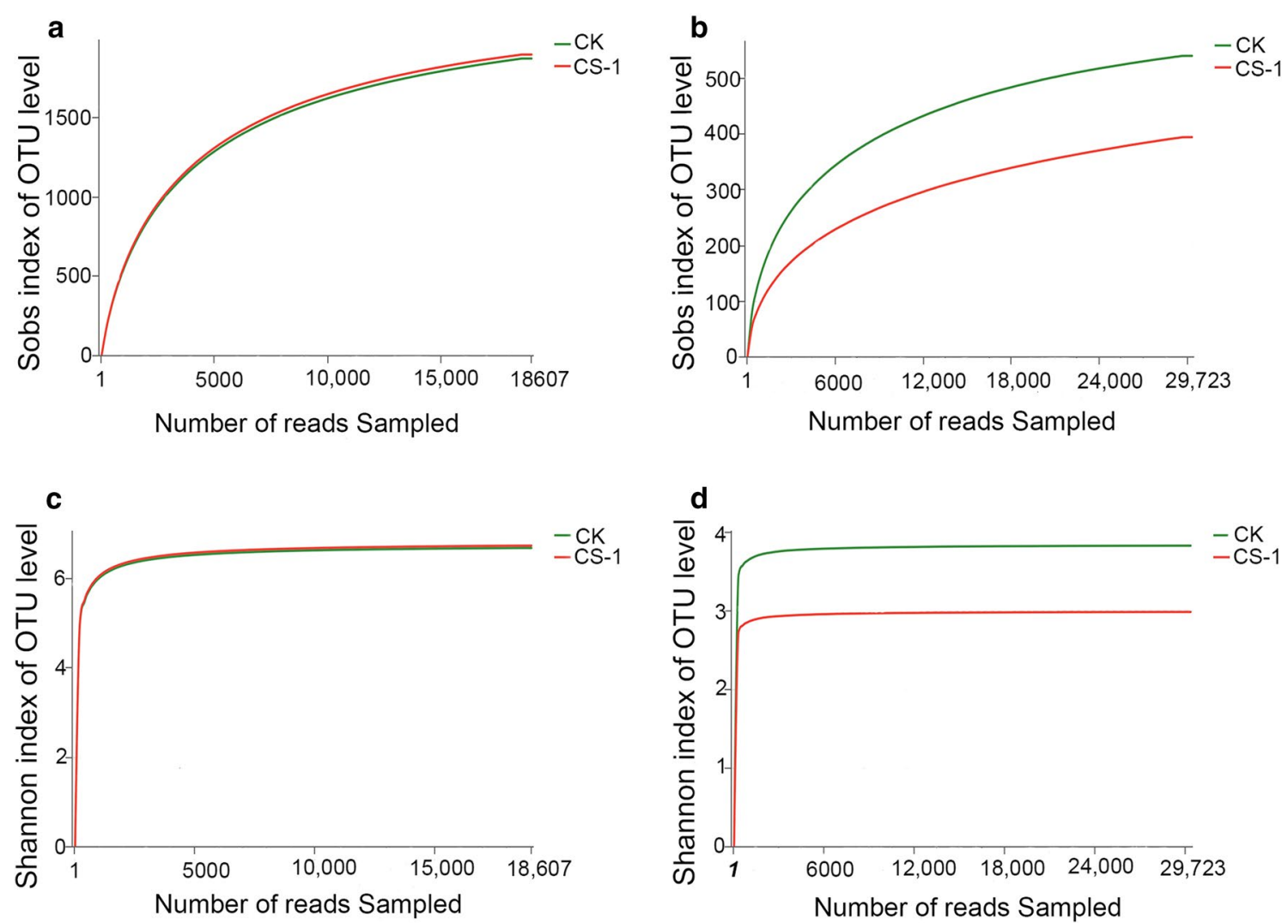

Fig. 3 Rarefaction and Shannon curve of CS-1 and control treatments. Fungal and bacterial rarefaction curves and Shannon curves depicting the effect of CS-1 and control treatments on the number of OTUs. a Rarefaction curves of bacteria from CS-1 and control treatments. b Rarefaction curves of fungi from CS-1 and control treatments. c Shannon curves of bacteria from CS-1 and control treatments. d Shannon curves of fungi from CS-1 and control treatments

community richness and diversity indices were calculated (Table 4); no significant differences observed between the two soil samples. The fungal community richness index is also presented in Table 4. The higher ACE and Chao values in the control samples indicated that the CS-1 strain treatment maintained a lower richness within the fungal community. The Simpson index and Shannon diversity index values showed a similar trend for fungal diversity.

\section{Comparison of bacterial communities in the CS-1 and control}

All bacterial sequences were classified at the phylum level down to the genus level using the Mothur program, and the relative abundances of the assigned phyla and genera were compared between the two samples. The overall bacterial composition and the distribution of each group in the different treatments were similar. At the phylum level, 11 and 13 bacteria phyla were detected in the control group and CS-1 treatment group, respectively (Fig. 4a, b), with Proteobacteria, Acidobacteria, Actinobacteria, and Chloroflexi the top four bacterial phyla. The average abundances of these phyla in the two treatment groups were $26.28,26.13,14.71$ and $13.80 \%$, respectively, in the control; and 25.74, 24.65, 16.10 and $14.56 \%$, respectively, in the CS-1 treatment group. At the order level, the bacterial composition and the relative abundance of the assigned groups also did not differ in the samples (Fig. 5a).

\section{Differences in fungal diversity between CS-1 treatment and control samples}

All fungal sequences were classified at the phylum level down to the genus level using the Mothur program. Three known fungal phyla were detected, with Ascomycota representing the most dominant phylum and accounting for 76.93 and $89.80 \%$ in the control groups and CS-1 treatments respectively (Fig. 4c, d). We found that the overall fungal composition in the different treatment groups was similar, while the distribution of each phylum or group varied (Fig. 5b). The surprising finding was that the content of Gibberella and Fusarium, which cause soil-borne diseases in wheat and other crops, were significantly lower in treatment than in the control, while the Aspergillus contents were significantly higher (Fig. 6). Furthermore, after mining useful information hidden in 

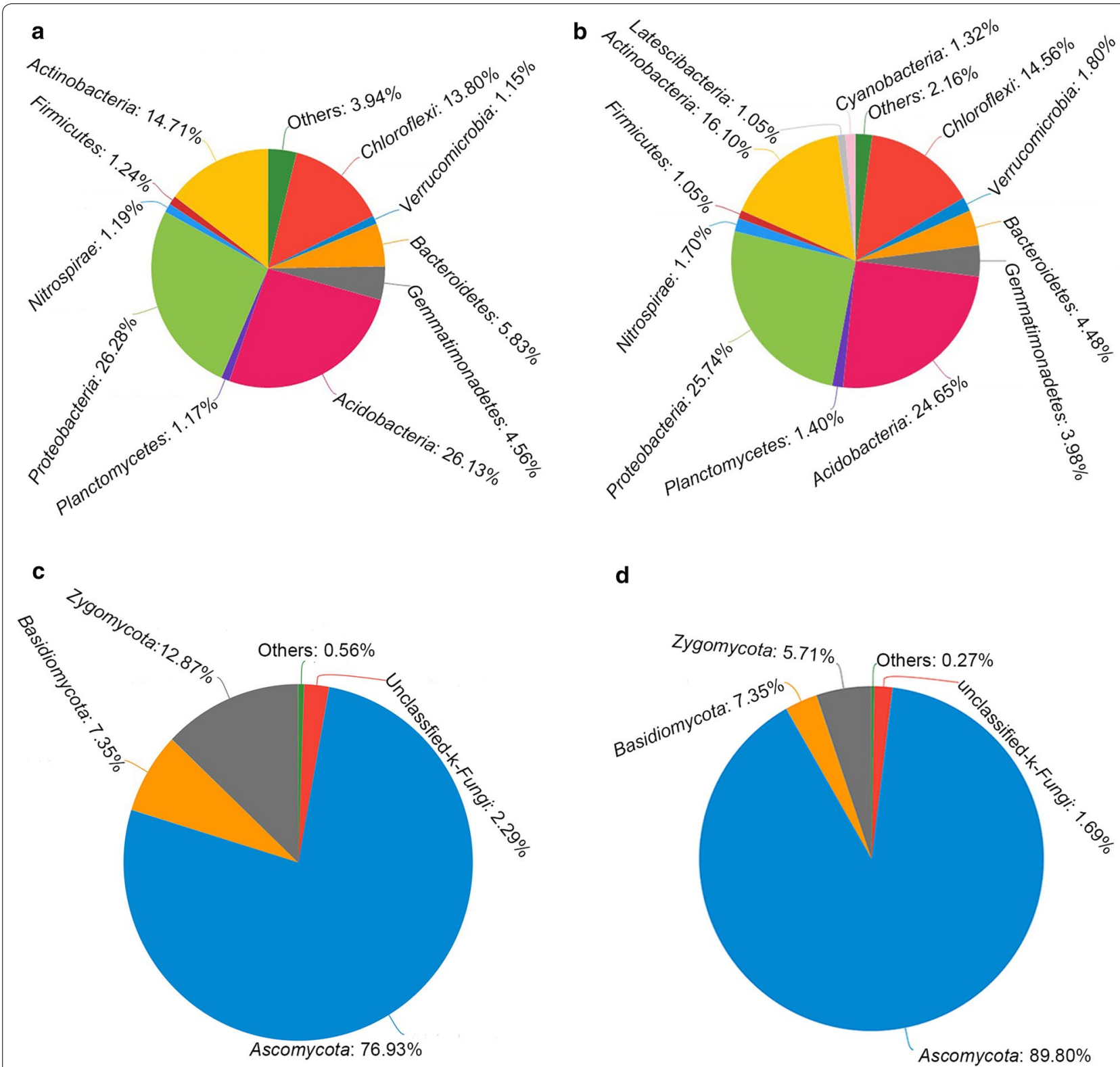

Fig. 4 Relative abundance of the dominant bacterial and fungal phyla in CS-1 and control treatment. The relative abundance (\%) of all bacteria and fungi on the phylum level in the rhizosphere soil of CS-1 and control treatments. a The relative abundance of all detected bacterial phyla after the control treatment. $\mathbf{b}$ The relative abundance of all detected bacterial phyla after the CS-1 treatment. $\mathbf{c}$ The relative abundance of all detected fungal phyla control treatment. d The relative abundance of all detected fungal phyla after the CS-1 treatment

the original data (Additional file 1: Table S1), the relative abundances of Monographella, Bipolaris, and Volutella in the CS-1 treatment group were found to decrease.

\section{Discussion}

Phosphate is a nutrient that is limiting for the growth of crops, with only $0.1 \%$ of total phosphorous in the soil available to plants (Vessey and Heisinger 2001). Although in China, the soil may harbor a total phosphorus reserve, it cannot be efficiently used by the plants because of low soil quality (Wu 2004). PSMs able to release phosphorus from the soil minerals play a key role in soil fertility (Wakelin et al. 2012) when P availability is low or P demand is high. Most relevant literature pertains to PSB and their potential use for the enhancement of soil fertility (Collavino et al. 2010; Ghosh et al. 2012). However, a few filamentous nonmycorrhizal fungi are also involved in phosphate solubilization, especially Aspergillus spp. 

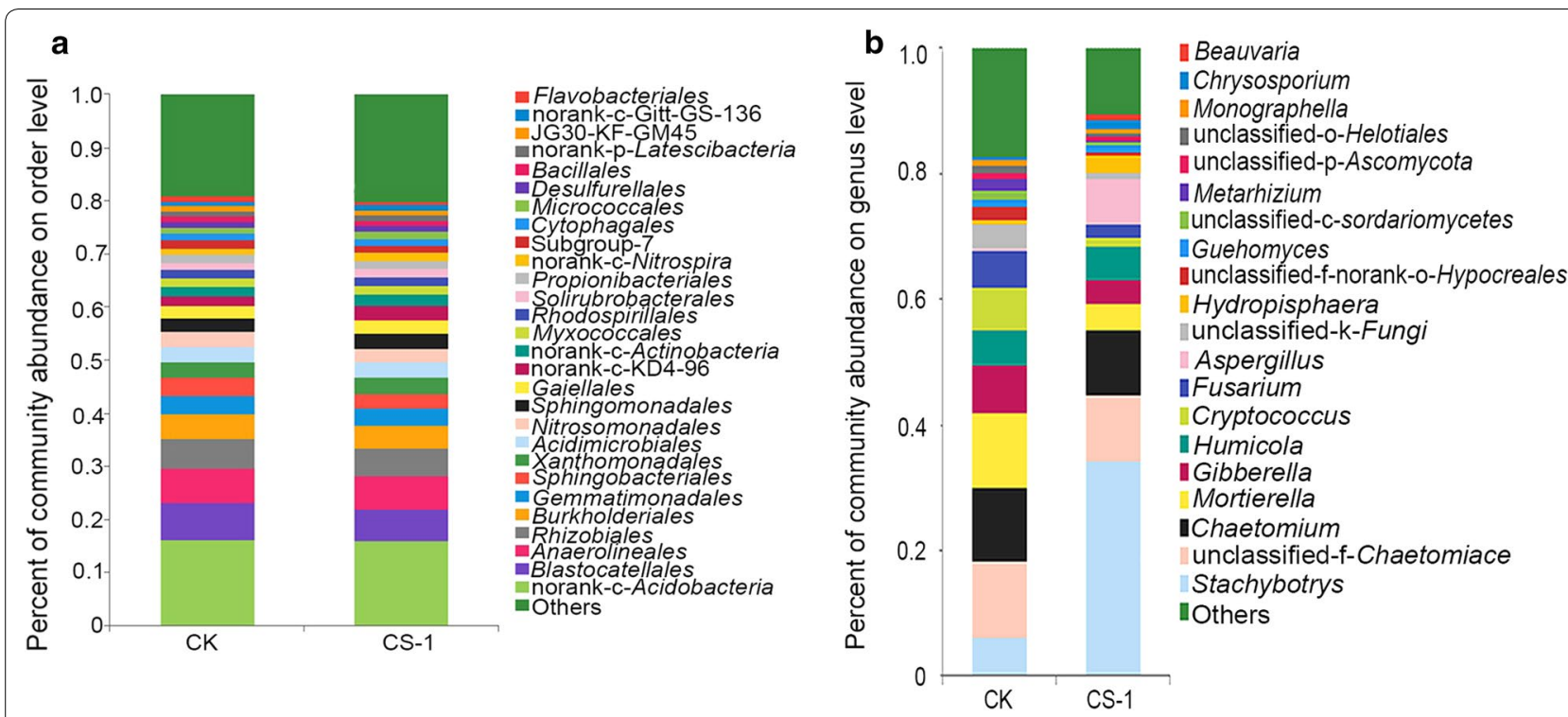

Fig. 5 Relative abundance of bacteria (genus levels) and fungi (order levels) in CS-1 and control treatments. The relative abundance (\%) of all bacteria (a) and fungi (b) on the order and genus levels, respectively, in the rhizosphere soil of CS-1 and control treatments

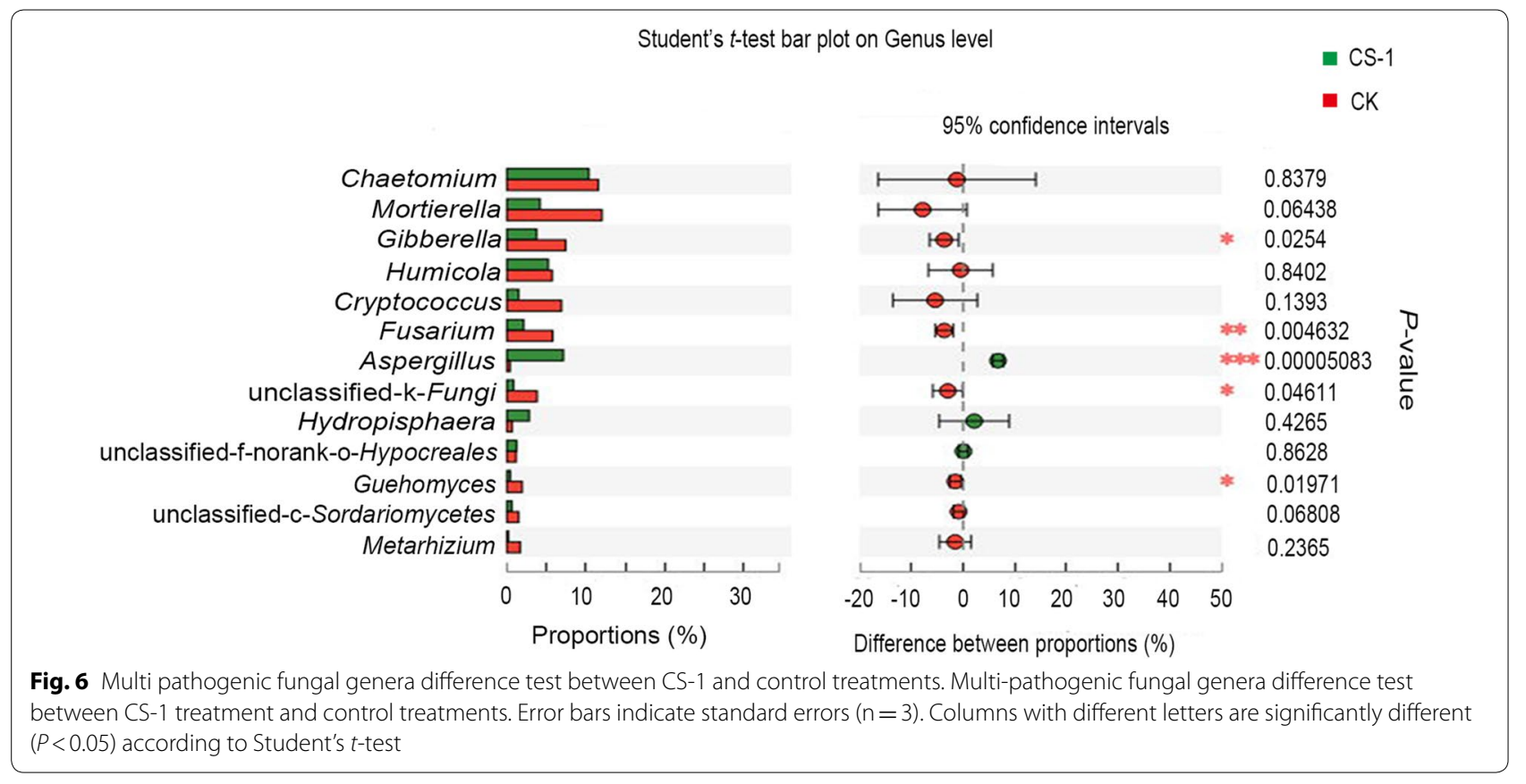

and Penicillium spp. (Altomare et al. 1999; Singh 2011). The beneficial effects for various crops of such phosphate-solubilizing fungi (PSF) as Aspergillus (Mittal et al. 2008), Trichoderma (Zayed and Abdelmotaal 2005), Penicillium (Reyes et al. 2002), and vesicular arbuscular mycorrhizae (Omar 1997) have been demonstrated.

In the present study, the formation of clear zones around the colonies on NBRIP medium indicated the phosphate-solubilizing ability of strain, with the extent of phosphate-solubilization determined quantitatively by liquid fermentation methods. Eight PSF strains were isolated on the NBRIP medium (Fig. 1). The results indicated that the NBRIP medium combined with the Martin agar medium supplemented with $30 \mu \mathrm{g} / \mathrm{mL}$ streptomycin constituted an effective method for isolating and screening of PSF from the rhizosphere soil samples. We report here the isolation of $A$. niger CS-1, which exhibited the highest phosphate-solubilizing ability among the eight fungal 
isolates tested. It is generally accepted that the major mechanism of mineral phosphate solubilization involves the action of organic acids synthesized by PSMs (Chabot et al. 1993; Morales et al. 2007). In the current study, the types and quantities of the organic acids secreted by strain CS-1 were analyzed by HPLC (Fig. 2). The major organic acids secreted by this strain were oxalic, tartaric, and citric acids, which was consistent with a previous report by Li et al. (2016). However, Tkacz and Lange demonstrated that the main organic acids produced by $A$. niger are gluconate, citrate, and oxalate (Tkacz and Lange 2004). This discrepancy may be associated with the different strain sources. Although the strains were identified as $A$. niger, they may exhibit some differences in the biosynthetic pathways and biological activities (Mäkelä et al. 2002; Yin et al. 2015). Moreover, the type of organic acids secreted by $A$. niger is also affected by the medium type and culture conditions (Altomare et al. 1999).

Enormous amounts of agricultural cellulosic wastes are accumulating because of the low efficiency and high cost of their utilization (Lee et al. 2008). It has been reported that fungi are potent cellulase and hemicellulase producers, and that, among fungal species, Aspergillus spp. notably produces copious amounts of such enzymes ( $\mathrm{Li}$ et al. 2014, 2015b; Pourramezan et al. 2012). In the current study, the CS-1 strain exhibited a better cellulosedegrading activity (Table 2) than other strains ( $\mathrm{Li}$ et al. 2003; Sachslehner et al. 1997; Pourramezan et al. 2012). It is worth noting that the carbon source in the growth medium considerably affects the synthesis of cellulolytic enzymes in liquid culture, with the highest amounts of cellulases produced by $A$. niger with sodium carboxymethylcellulose as a carbon source (Gautam et al. 2010).

An important quality for the potential use of PSMs growth-stimulating ability upon when plants are inoculation (Collavino et al. 2010). Accordingly, the strain $A$. niger CS-1 promoted plant growth by increasing the fresh and dry mass of wheat per plant in pot experiments. It is generally accepted that PSF solubilize elemental phosphorus from insoluble RP for plant growth. To reveal the mechanism underpinning the plant growth-promoting effect of the CS-1 strain, Illumina MiSeq sequencing was used to characterize the soil microorganism communities after control and CS-1 treatments. Understanding the ecology of these taxa is important as it may provide new insights about soil biological resources to foster sustainable agricultural production (Adesemoye and Kloepper 2009; Wakelin et al. 2012).

Proteobacteria, Actinobacteria, Acidobacteria, and Chloroflexi were the four most dominant phyla in the control and CS-1-treated samples. The Proteobacteria phylum includes many of the bacteria responsible for nitrogen fixation (Chen et al. 2003; Wang et al. 2015) and a wide variety of pathogens (Tsolis 2002). Actinobacteria play an important role in the decomposition and humus formation processes (Kopecky et al. 2011). The ecology and metabolism of Acidobacteria is not well understood because the majority of these bacteria have not been cultured (Sun et al. 2014). Chloroflexi constitutes a specialized group of filamentous bacteria that are only active under aerobic conditions, consume primarily carbohydrates, and contribute to the overall filament index (Kragelund et al. 2007). Nevertheless, no significant differences were apparent between the two treatment treatments analysis on the phylum level or the order level. Surprisingly, the experiment revealed that the inoculation with the CS-1 strain reduced the diversity of the soil fungal communities (Table 4), although the overall fungal community composition was largely unaffected. The differences between the control and CS-1 treatments were reflected in the distribution of each fungal group, including uncultured species. This indicated that the impact of the CS-1 strain on the microbial community in the wheat rhizosphere was complex, and particularly, led to a significant reduction of the content of pathogenic fungi. It is worth noting that the CS-1 strain did not hinder the growth of plant pathogens (such as Fusarium oxysporum, Bipolaris sorokiniana, and Gibberella fujikuroi) during dual-plate confrontation assays on potato dextrose agar plates (There's no data show). Hence, the CS-1 inoculation effect may be associated with an ecological niche competition, because the relative abundance of Aspergillus spp. increased significantly in the CS-1 treatment group, whereas these fungi were undetected in the control group. To the best of our knowledge, this is the firstever report demonstrating the effect of $A$. niger on the microbial community structure.

In conclusion, in the current study, we isolated an efficient phosphofungus, CS-1, which was subsequently identified as $A$. niger. This is the first study to comprehensively elaborate the mechanisms of $A$. niger activity as a plant growth promoting rhizobacteria (PGPR), including phosphorus and potassium solubilization, cellulase and hemicellulase activity, and inhibition of pathogenic fungi in the crop rhizosphere soil. Further, the CS-1 strain exhibited marked growth-promoting effects on wheat seedlings. Owing to its multiple beneficial effects, the $A$. niger CS-1 strain has the potential to be developed and commercially formulated as a commercial microbial agent for field application.

\section{Additional file}

Additional file 1: Fig. S1. Effect of the CS-1 strain on root length and shoot height of wheat seedings. As compared with control, wheat seedlings treated with this strain had a greater number of tillers and lateral roots. Table S1. Percent of pathogenic fungi abundance. 


\begin{abstract}
Abbreviations
RP: rock phosphate; PSMs: phosphate-solubilizing microorganisms; NBRIP: National Botanical Research Institute's phosphate; ITS: internal transcribed spacer; PSF: phosphate-solubilizing fungal; HPLC: high-performance liquid chromatography; TCP: tricalcium phosphate; PSB: phosphate-solubilizing bacteria; PGPR: plant growth promoting rhizobacteria; BLAST: Basic Local Alignment Search Tool.
\end{abstract}

\section{Authors' contributions}

XHW and XLL conceived and designed the study the study. XHW, CDW, QL, CQW, JMZ and JFD performed experiments. XHW, JKS, ZYLand RBS analyzed the data, and prepared figures and tables. XHW and CDW wrote the manuscript. CJ, XS and YRH reviewed polished the paper. All authors read and approved the final manuscript.

\section{Author details}

${ }^{1}$ College of Life Science, Shandong Agriculture University, No. 61, Daizong Street, Taian, Shandong, China. ${ }^{2}$ College of Forestry, Shandong Agricultural Universities, No. 61, Daizong Street, Taian 271018, Shandong, China.

\section{Acknowledgements}

We would like to thank Editage (http://www.editage.cn) for English language editing of the manuscript.

\section{Competing interests}

The authors declare that they have no competing interests.

\section{Availability of data and materials}

The strain CS-1 was identified as Aspergillus niger and has been deposited in the China General Microbiological Culture Collection Center (CGMCC) under the accession numbers CGMCC No. 14634. Raw Illumina sequencing data from the current study were submitted to the NCBI Sequence Read Archive (SRA) under the accession number SRP132621.

\section{Consent for publication}

Not applicable.

\section{Ethics approval and consent to participate}

This article does not contain any studies with human participants or animals performed by any of the authors.

\section{Funding}

This work was supported by the Special Fund for Agro-scientific Research in the Public Interest (No. 201503112) and the Forestry Industry Research special funds for public welfare projects (No. 201304212). The work was also supported by the Funds of from the Shandong forestry science and technology innovation project and Shandong "Double Tops" Program.

\section{Publisher's Note}

Springer Nature remains neutral with regard to jurisdictional claims in published maps and institutional affiliations.

Received: 1 April 2018 Accepted: 13 April 2018

Published online: 20 April 2018

\section{References}

Abarenkov K, Henrik NR, Larsson KH, Alexander IJ, Eberhardt U, Erland S, Høiland K, Kjøller R, Larsson E, Pennanen T (2010) The UNITE database for molecular identification of fungi-recent updates and future perspectives. New Phytol 186(2):281-285

Adesemoye AO, Kloepper JW (2009) Plant-microbes interactions in enhanced fertilizer-use efficiency. Appl Microbiol Biotechnol 85(1):1-12

Altomare C, Norvell WA, Harman RE (1999) Solubilization of Phosphates and Micronutrients by the Plant-Growth-Promoting and Biocontrol Fungus Trichoderma harzianum Rifai 1295-22. Appl Environ Microbiol 65(7):2926-2933
Bonito G, Hameed K, Ventura R, Krishnan J, Schadt CW, Vilgalys R (2016) Isolating a functionally relevant guild of fungi from the root microbiome of Populus. Fungal Biol 22:35-42

Bray R (1945) Determination of total, organic and available forms of phosphorus in soils. Soil Sci 59(1):39-46

Chabot R, Antoun H, Cescas MP (1993) Growth stimulation of corn and romaine lettuce by microorganisms solubilizing inorganic phosphorus. Can J Microbiol 39(10):941-947

Chai B, Wu Y, Liu P, Liu B, Gao M (2011) Isolation and phosphate-solubilizing ability of a fungus, Penicillium sp. from soil of an alum mine. J Basic Microbiol 51(1):5

Chen WM, Moulin L, Bontemps C, Vandamme P, Béna G, Boivin-Masson C (2003) Legume symbiotic nitrogen fixation by $\beta$-proteobacteria is widespread in nature. J Bacteriol 185(24):7266-7272

Collavino MM, Sansberro PA, Mroginski LA, Aguilar OM (2010) Comparison of in vitro solubilization activity of diverse phosphate-solubilizing bacteria native to acid soil and their ability to promote Phaseolus vulgaris growth. Biol Fert Soil 46(7):727-738

Gautam SP, Bundela PS, Pandey AK, Awasthi MK (2010) effect of different carbon sources on production of cellulases by Aspergillus niger. J Appl Sci Environ Sanitat 5(3):277-281

Ghosh U, Subhashini P, Dilipan E, Raja S, Thangaradjou T, Kannan L (2012) Isolation and characterization of phosphate-solubilizing bacteria from seagrass rhizosphere soil. J Ocean Univ China 11(1):86-92

Gyaneshwar P, Kumar GN, Parekh $\sqcup$ (1998) Effect of buffering on the phosphate-solubilizing ability of microorganisms. World J Microb Biotechnol 14(5):669-673

Huang BL, ChengQun L (2010) Isolation and characterization of azotobacteria from pine rhizosphere. Afr J Microbiol Res 4(12):1299-1306

Joseph S, Jisha MS (2009) Buffering reduces phosphate solubilizing ability of selected strains of bacteria. World J Agric Sci 5(1):135-137

Kopecky J, Kyselkova M, Omelka M, Cermak L, Novotna J, Grundmann GL, Moënne-Loccoz Y, Sagova-Mareckova M (2011) Actinobacterial community dominated by a distinct clade in acidic soil of a waterlogged deciduous forest. FEMS Microbiol Ecol 78(2):386-394

Kragelund C, Levantesi C, Borger A, Thelen K, Eikelboom D, Tandoi V, Kong Y, Van der Waarde J, Krooneman J, Rossetti S (2007) Identity, abundance and ecophysiology of filamentous Chloroflexi species present in activated sludge treatment plants. FEMS Microbiol Ecol 59(3):671-682

Lee YJ, Kim BK, Lee BH, Jo KI, Lee NK, Chung CH, Lee YC, Lee JW (2008) Purification and characterization of cellulase produced by Bacillus amyloliquefaciens DL-3 utilizing rice hull. Bioresour Technol 99(2):378-386

Li X, Dong X, Zhao C, Zhen C, Feng C (2003) Isolation and some properties of cellulose-degrading Vibrio sp. LX-3 with agar-liquefying ability from soil. World J Microbiol Biotechnol 19(4):375-379

Li Q, Wei TN, Jin CW (2014) Isolation, characterization and application of a cellulose-degrading strain Neurospora crassa S1 from oil palm empty fruit bunch. Microb Cell Fact 13(1):157

Li F, Wang Z, Dai J, Li Q, Wang X, Xue C, Liu H, He G (2015a) Fate of nitrogen from green manure, straw, and fertilizer applied to wheat under different summer fallow management strategies in dryland. Biol Fert Soils 51(7):769-780

Li F, Xie J, Zhang X, Zhao L (2015b) Improvement of the optimum pH of Aspergillus niger xylanase towards an alkaline $\mathrm{pH}$ by site-directed mutagenesis. J Microbiol Biotechnol 25(1):11

Li Z, Bai T, Dai L, Wang F, Tao J, Meng S, Hu Y, Wang S, Hu S (2016) A study of organic acid production in contrasts between two phosphate solubilizing fungi: Penicillium oxalicum and Aspergillus niger. Sci Rep 6:25313

Liang Y, Lei Z, Chunping HE, Zheng X, Shuhua YU, Zheng F (2011) Phosphatesolubilizing mechanism of PSFM and preliminary study on solubilization capacity of insoluble phosphates. Chin J Trop Crops 32(6):1116-1121

Liu P, Wang XH, Li JG et al (2015) Pyrosequencing reveals fungal communities in the rhizosphere of Xinjiang Jujube. Biomed Res Int 2015:972481

Mäkelä M, Galkin S, Hatakka A, Lundell T (2002) Production of organic acids and oxalate decarboxylase in lignin-degrading white rot fungi. Enzyme Microb Technol 30(4):542-549

Mehta S, Nautiyal CS (2001) An efficient method for qualitative screening of phosphate-solubilizing bacteria. Curr Microbiol 43(1):51

Mendes GDO, Vassilev NB, Bonduki VHA, Silva IRD Jr, Ribeiro Jl, Costa MD (2013) Inhibition of Aspergillus niger phosphate solubilization by fluoride released from rock phosphate. Appl Environ Microbiol 79(16):4906-4913 
Mendez J (2014) Characterization of phosphate-solubilizing bacteria isolated from the arid soils of a semi-desert region of north-east Mexico. Biol Agric Hortic 30(3):211-217

Miller GL (1959) Use of dinitrosalicylic acid reagent for determination of reducing sugar. Anal Biochem 31(3):426-428

Mittal V, Singh O, Nayyar H, Kaur J, Tewari R (2008) Stimulatory effect of phosphate-solubilizing fungal strains (Aspergillus awamori and Penicillium citrinum) on the yield of chickpea (Cicer arietinum L. Cv. GPF2). Soil Bio Biochem 40(3):718-727

Morales A, Alvear M, Valenzuela E, Rubio R, Borie F (2007) Effect of inoculation with Penicillium albidum, a phosphate-solubilizing fungus, on the growth of Trifolium pratense cropped in a volcanic soil. J Basic Microb 47(3):275-280

Nahas E (1996) Factors determining rock phosphate solubilization by microorganisms isolated from soil. World J Microbiol Biotechnol 12(6):567-572

Nautiyal CS, Bhadauria S, Kumar P, Lal H, Mondal R, Verma D (2000) Stress induced phosphate solubilization in bacteria isolated from alkaline soils. FEMS Microbiol Lett 182(2):291

Omar SA (1997) The role of rock-phosphate-solubilizing fungi and vesiculararbusular-mycorrhiza (VAM) in growth of wheat plants fertilized with rock phosphate. World J Microbiol Biotechnol 14(2):211-218

Pitkäranta M, Meklin T, Hyvärinen A, Paulin L, Auvinen P, Nevalainen A, Rintala $H$ (2008) Analysis of fungal flora in indoor dust by ribosomal DNA sequence analysis, quantitative PCR, and culture. Appl Environ Microbiol 74(1):233

Ponmurugan P, Gopi C (2006) Distribution pattern and screening of phosphate solubilizing bacteria isolated from different food and forage crops. J Agron 5(4):600-604

Pourramezan Z, Ghezelbash GR, Romani B, Ziaei S, Hedayatkhah A (2012) Screening and identification of newly isolated cellulose-degrading bacteria from the gut of xylophagous termite Microcerotermes diversus (Silvestri). Microbiology 81(6):796-802

Ram H, Malik SS, Dhaliwal SS, Kumar B, Singh Y (2015) Growth and productivity of wheat affected by phosphorus-solubilizing fungi and phosphorus levels. Plant Soil Environ 61(3):122-126

Reddy GK, Sudhakara M (2014) Role of phosphate-solubilizing bacteria in improving the soil fertility and crop productivity in organic farming. Arch Agron Soil Sci 60(4):549-564

Reyes I, Bernier L, Antoun H (2002) Rock phosphate solubilization and colonization of maize rhizosphere by wild and genetically modified strains of Penicillium rugulosum. Microb Ecol 44(1):39-48

Rmn K (1983) Phosphate-solubilizing bacteria and fungi in various cultivated and virgin Alberta soils. Can J Soil Sci 63(4):671-678

Rodríguez H, Fraga R (1999) Phosphate solubilizing bacteria and their role in plant growth promotion. Biotechnol Adv 17(4-5):319-339

Sachslehner A, Haltrich D, Nidetzky B, Kulbe KD (1997) Production of hemicellulose- and cellulose-degrading enzymes by various strains of Sclerotium Rolfsii. Appl Biochem Biotechnol 65(1):189-201
Schloss PD, Westcott SL, Ryabin T, Hall JR, Hartmann M, Hollister EB, Lesniewski RA, Oakley BB, Parks DH, Robinson CJ (2009) Introducing mothur: open-source, platform-independent, community-supported software for describing and comparing microbial communities. Appl Environ Microbiol 75(23):7537

Singh $\mathrm{H}$ (2011) Effect of inoculation with phosphate solubilizing fungus on growth and nutrient uptake of wheat and maize plants fertilized with rock phosphate in alkaline soils. Eur J soil Biol 47(1):30-34

Sulbarán M, Pérez E, Ball MM, Bahsas A, Yarzábal LA (2009) Characterization of the mineral phosphate-solubilizing activity of Pantoea agglomerans MMB051 isolated from an iron-rich soil in southeastern Venezuela (Bolivar State). Curr Microbiol 58(4):378-383

Sun J, Zhang Q, Zhou J, Wei Q (2014) Pyrosequencing technology reveals the impact of different manure doses on the bacterial community in apple rhizosphere soil. Appl Soil Ecol 78(6):28-36

Tkacz JS, Lange L (2004) Advances in fungal biotechnology for industry, agriculture and medicine. Springer, Berlin

Tsolis RM (2002) Comparative genome analysis of the proteobacteria: relationships between plant and animal pathogens and host specificity. Proc Nat Acad Sci USA 99(20):12503-12505

Vessey JK, Heisinger KG (2001) Effect of Penicillium bilaii inoculation and phosphorus fertilisation on root and shoot parameters of field-grown pea. Can J Plant Sci 81(3):361-366

Wakelin S, Mander C, Gerard E, Jansa J, Erb A, Young S, Condron L, O'Callaghan M (2012) Response of soil microbial communities to contrasted histories of phosphorus fertilisation in pastures. Appl Soil Ecol 61(5):40-48

Wang H, He Q, Chen D, Wei L, Zou Z, Zhou J, Yang K, Zhang H (2015) Microbial community in a hydrogenotrophic denitrification reactor based on pyrosequencing. Appl Microbiol Biotechnol 99(24):10829-10837

Wei Y, Zhao Y, Fan Y, Lu Q, Li M, Wei Q, Zhao Y, Cao Z, Wei Z (2017) Impact of phosphate-solubilizing bacteria inoculation methods on phosphorus transformation and long-term utilization in composting. Bioresour Technol 241:134

Wu C (2004) Chinese phosphate resources situation and recommendations for sustainable supply. J Chem Fertilizer Ind 31(4):3-5

Yin Z, Shi F, Jiang H, Roberts DP, Chen S, Fan B (2015) Phosphate solubilization and promotion of maize growth by Penicillium oxalicum P4 and AspergilIus niger P85 in a calcareous soil. Can J Microbiol 61(12):913

Zayed G, Abdelmotaal H (2005) Bio-active composts from rice straw enriched with rock phosphate and their effect on the phosphorous nutrition and microbial community in rhizosphere of cowpea. Bioresour Technol 96(8):929-935

Zheng J, Xiao X, Zhang Q, Mao L, Yu M, Xu J (2015) The placental microbiome varies in association with low birth weight in full-term neonates. Nutrients 7(8):6924-6937

\section{Submit your manuscript to a SpringerOpen ${ }^{\circ}$ journal and benefit from:}

- Convenient online submission

- Rigorous peer review

- Open access: articles freely available online

- High visibility within the field

- Retaining the copyright to your article

Submit your next manuscript at springeropen.com 